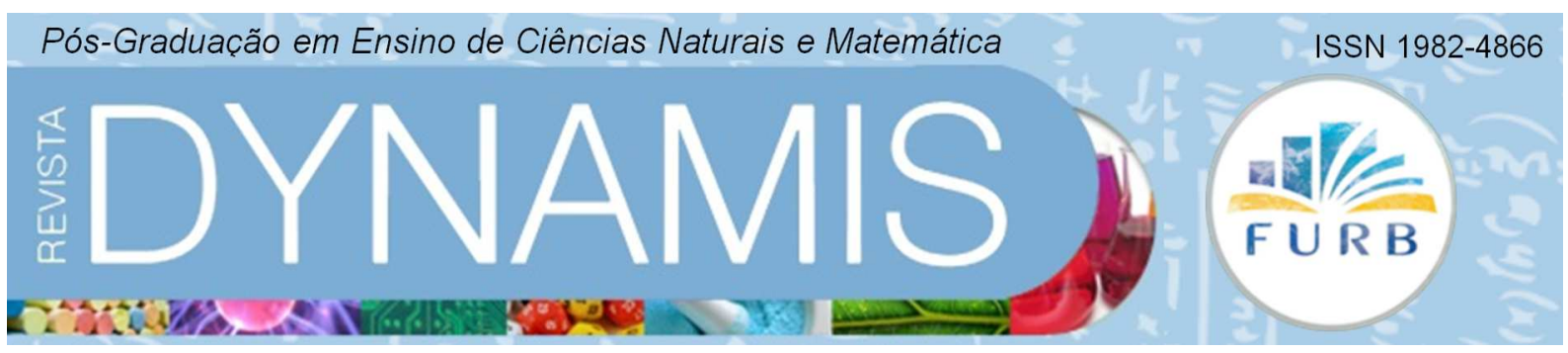

\title{
A MODELAGEM MATEMÁTICA NOS CURSOS DE LICENCIATURA EM MATEMÁTICA DO ESTADO DO PARANÁ
}

Exploiting the idea of chance in random events, from a teaching sequence

Guataçara dos Santos Junior

Programa de Pós-Graduação em Ensino de Ciência e Tecnologia

Universidade Tecnológica Federal do Paraná

guata@utfpr.edu.br

Maria Rosana Soares

Universidade Tecnológica Federal do Paraná

maryrosana@uol.com.br 


\title{
Resumo
}

A modelagem matemática como disciplina é essencial para que se contribua com a formação qualificada dos futuros professores de Matemática. Assim, objetivou-se analisar as faculdades/universidades do estado do Paraná que oferecem a disciplina de modelagem matemática inserida na matriz curricular nos cursos de Licenciatura em Matemática.O presente estudo desenvolveu-se à luz da pesquisa qualitativa, no qual a coleta de dados se deu por meio da observação e análise do material obtido nos endereços eletrônicos das instituições de ensino superior cadastradas no "e-mec". Os resultados apontaram que a maioria dessas faculdades/universidades não insere a modelagem matemática na matriz curricular do curso mencionado. Logo, diversos licenciandos poderão não obter uma preparação para trabalhá-la no ensino e terem dificuldades para reconhecer sua importância no ensino e aprendizagem de Matemática.

Palavras-chave: Educação Matemática. Modelagem Matemática. Licenciatura em Matemática.

\begin{abstract}
Mathematical Modellingas a disciplineis essentialto contributeto the educationof futureteachers of mathematics. Therefore, we aimed at analyzingthe colleges/universities in the stateof Parana, whichofferthe disciplinemathematical modellingembedded inthe curriculumof undergraduate coursesin Mathematics. The present study was developedin the lightof qualitative researchin whichthe data collectionwas held throughobservation andanalysis of the materialin the electronic addresses of higher educationinstitutions registeredin"e-mec". The results indicated that most of these colleges/universities donot insert mathematical modelling in the curriculum of the courses mentioned.Soon, manyundergraduatesmaynot obtaina preparation towork with itinschools andthey will havedifficultiesto recognizeits importanceto theteaching and learningof Mathematics.
\end{abstract}

Keywords: Mathematics Education. Mathematical Modelling. Degree in Mathematics. 


\section{INTRODUÇÃO}

A Matemática é um elemento fundamental para a formação reflexiva e sociocultural, à progressão humana da capacidade de pensar, agir, resolver e entender os problemas do dia a dia, assim como para exercer a cidadania no meio social, econômico e tecnológico. Na sua evolução, ela passou por várias mudanças, aprimorando seu contexto ao longo da história e se tornando cada vez mais importante para a permanência das pessoas no mundo do trabalho e para uma revolução da sociedade. Com o objetivo de desmistificar sua complexidade, surgiram novas tendências de ensino diferenciando e significando a Matemática por meio de uma abordagem dinâmica aplicada ao ensino e aprendizagem, proporcionando mais uma opção de trabalho. Entre tais tendências pedagógicas tem-se a Modelagem Matemática.

Bassanezi (2009, p.177) afirma que a utilização da Modelagem como uma estratégia de ensino e aprendizagem é um dos caminhos para tornar os cursos de Matemática, em qualquer nível, mais atraentes e agradáveis. Segundo Barbosa (2003) e Blum (1995) a Modelagem como estratégia de ensino permite estimular os alunos para sua motivação, facilitando a aprendizagem, incluindo uma preparação para utilizar a matemática em diferentes áreas e o desenvolvimento de habilidades gerais de exploração e compreensão do papel sociocultural da Matemática. A Modelagem é uma alternativa pedagógica de pesquisa que busca apresentar a Matemática presente no cotidiano, proporcionando a análise e reflexão sobre sua utilização nos contextos sociais, culturais, em fenômenos e em várias situações reais permitindo investigá-la, interpretá-la e explicá-la diante dos problemas formulados da realidade.

A Modelagem como disciplina é essencial para contribuir para a formação qualificada dos futuros professores e para a melhoria do ensino e aprendizagem de Matemática. Logo, ela, no ensino de Matemática e de outras áreas, permite que os assuntos discutidos partam de situações concretas, valoriza o trabalho em grupo no qual o professor assume o papel de mediador e o aluno de autônomo, e os problemas são formulados conforme os temas abordados, e assim por diante. As diferentes práticas e pesquisas de Modelagem no ensino têm possibilitado a obtenção de resultados satisfatórios tanto para os alunos quanto para os professores.

Com as considerações apresentadas, definiu-se o seguinte problema: Que faculdades/universidades do estado do Paraná oferecem a disciplina de Modelagem inserida na matriz curricular nos cursos de Licenciatura em Matemática?

$\mathrm{Na}$ busca pela resposta do problema de pesquisa tem-se o objetivo geral de analisar as faculdades/universidades do estado do Paraná que oferecem a disciplina de Modelagem inserida na matriz curricular nos cursos de Licenciatura em Matemática.

\section{A MODELAGEM MATEMÁTICA NO CURSO DE LICENCIATURA EM MATE- MÁTICA}

A Matemática apresenta duas correntes predominantes quando se refere aos seus objetivos, "uma, que lhe dá o caráter de ser uma ciência que não necessita retribuir coisa alguma ao mundo exterior e, outra, que procura achar uma ligação, de cada especialidade, com alguma área de aplicação" (BASSANEZI, 2009, p. 179). Essas correntes se encontram nos projetos de ensino procurando ganhar espaço nos campos de pesquisas dos cursos de Matemática como os de licenciaturas e bacharelados, valorizando a construção de modelos e suas aplicações na sociedade. Nota-se o cenário de alguns cursos de Licenciatura em Matemática: 
De modo paralelo aos cursos de matemática aplicada, as disciplinas oferecidas no curso de Licenciatura em Matemática, cujo objetivo é formar docentes para o ensino fundamental e médio, continuam funcionando no estilo clássico formalista. Sem dúvida, aproximando a nossa afirmação do terreno das conjeturas, com tal formação purista, os futuros profissionais só podem reconhecer a utilidade da Matemática na capacidade desta de ensinar a pensar e raciocinar com precisão. (BASSANEZI, 2009, p. 179).

O curso de Licenciatura em Matemática objetiva preparar profissionais qualificados para atuar na educação básica, visto que diversos cursos desta área se encontram organizados e fundamentados no modelo sistemático de ensino e assim as disciplinas são abordadas de modo independente.

O cenário dos cursos de Licenciatura em Matemática é explicado assim:

\begin{abstract}
A falta de objetividade da maioria dos cursos de Licenciatura em Matemática provoca uma angústia nos formandos que se sentem incapacitados para exercerem o magistério. Os programas desenvolvidos nas diferentes disciplinas quase sempre são fechados e não existe uma interligação com outras ciências - a ênfase maior está na quantidade de conteúdo transmitido e não na formação de elementos atuantes na sociedade. Desse modo, quando pensamos num professor de Matemática, formado nesses termos - o que é realidade em quase todo país - facilmente reconhecemos as dificuldades que ele terá de superar de modo a tornar suas aulas mais interessantes, isto é, conseguir que os alunos participem efetivamente. Na verdade, este problema é geral, porém, nos países em desenvolvimento ele é muito mais sensível que nos países ditos desenvolvidos, dado que a própria dinâmica da evolução científica acaba orientando a busca de tendências mais técnicas e aplicativas. (BASSANEZI, 2009, p. 180-181).
\end{abstract}

Nesse sentido, a necessidade e relevância de despertar o interesse do aluno e sanar suas dificuldades em relação a esta disciplina tornou-se uma preocupação dos profissionais da área. Isso porque a falta de motivação para a Matemática está se tornando um problema sério nas instituições de ensino. Com esse objetivo, surgiram novas tendências da Educação Matemática que buscam auxiliar a prática docente tornando as aulas desta disciplina mais atraente para os alunos ao apresentá-la de modo contextualizado, por meio de problemas da realidade, com a intenção de contribuir para o ensino de Matemática.

Em se tratando especificamente da Modelagem Matemática, na concepção de Bassanezi (2009, p.24), é um processo dinâmico que se utiliza para a obtenção e validação de modelos matemáticos, é uma forma de abstração e generalização com a finalidade de previsão de tendências. Chevallard (2001, p.50) considera que ao ser abordada a elaboração de modelos:

Um aspecto essencial da atividade matemática consiste em construir um modelo (matemático) da realidade que se quer estudar, trabalhar com tal modelo e interpretar os resultados obtidos nesse trabalho, para responder as questões inicialmente apresentadas. Grande parte da atividade matemática pode ser identificada, portanto, como uma atividade de modelagem matemática.

Esse enfoque, o qual permite investigar-se e analisar-se uma situação da realidade, na qual se busca fazer a formulação e resolução de problemas para a linguagem matemática 
procurando-se solucionar ou deduzir o problema formulado, e proporcionando-se aos alunos atribuição de sentidos e construção de significados, denomina-se modelo matemático. Este pode ser entendido como solução do problema da atividade de Modelagem, ou seja, a representação matemática que pode ser expressa por meio de conjuntos, símbolos, estruturas e relações matemáticas como gráficos, tabelas, funções, sistemas, equações, diagramas, figuras geométricas, representações estatísticas, expressões matemáticas e por outros elementos matemáticos e recursos computacionais.

No entendimento de Bassanezi (2009, p.16), a Modelagem "consiste na arte de transformar problemas da realidade em problemas matemáticos e resolvê-los interpretando suas soluções na linguagem do mundo real". De acordo com Barbosa (2001, p.46), ela é "um ambiente de aprendizagem no qual os alunos são convidados a problematizar e investigar, por meio da matemática, situações com referência na realidade". A Modelagem é a estratégia de ensino e aprendizagem que proporciona investigar, problematizar e transformar as situações da realidade em representação matemática, ou seja, em modelo matemático.

Nessa perspectiva, é essencial relatar como ocorreu o início da Modelagem:

\begin{abstract}
O interesse em trabalhar com modelagem matemática surgiu quando, numa reunião com professores de Cálculo de algumas instituições do Sul do país em 1981, percebemos o distanciamento entre a prática pedagógica e a participação efetiva do educador no meio em que está inserido. Nesta experiência, ficou clara a dificuldade de se elaborar um problema novo. A criatividade, a busca de situações novas ou mesmo o interesse em valorizar seu trabalho como educadores estavam resumidos aos assuntos e problemas dos livros didáticos adotados, quase sempre divorciados do ambiente e da realidade de cada um. (BASSANEZI, 2009, p.203).
\end{abstract}

A Modelagem no ensino não foi um trabalho simples tanto para os docentes quanto para os discentes. Eles não estavam habituados com o processo de Modelagem como a formulação de problemas, a obtenção do modelo matemático, e este cenário ainda é observado em várias escolas, faculdades e/ou universidades.

Inicialmente, a Modelagem foi proposta em forma de curso:

\begin{abstract}
O primeiro curso realizado com Modelagem Matemática deu-se num programa de aperfeiçoamento de professores, na Faculdade Estadual de Filosofia, Ciências e Letras de Guarapuava-PR (FAFIG), atual Universidade Estadual Centro-Oeste (UNICENTRO), sendo um ano depois da experiência na Universidade Estadual de Campinas (UNICAMP) com os professores de Cálculo. Tínhamos elaborado inicialmente um programa para reciclagem de professores do ensino superior, com módulos de Cálculo Diferencial e Integral, Análise, Topologia, e outros. (BASSANEZI, 2009, p.203).
\end{abstract}

Entende-se que a Modelagem teve seu início sob a organização de cursos, os quais buscavam oferecer uma preparação profissional aos professores ao relacionar a teoria e a prática com a finalidade de contribuir ao ensino e aprendizagem de Matemática. Isso proporcionou motivá-los para trabalhá-la em sala de aula, visto que seus cursos e práticas vinham crescendo e consolidando-se gradativamente no país.

A Modelagem teve seu início como estratégia de ensino e aprendizagem: 


\begin{abstract}
Nossa surpresa foi verificar que, entre os participantes do curso realizado na FAFIG, a maioria era de professores da rede de ensino fundamental e médio, que tinham cursado o programa de Licenciatura Curta, ainda em voga em quase toda a universidade do Paraná. Fizemos, então, uma mudança na proposta inicial, não em sua essência, mas na abrangência, pois o curso não deveria se limitar apenas aos conteúdos do ensino superior, mas a uma matemática geral que pudesse se constituir num projeto passível de utilização em classes de ensino básico. Nestas circunstâncias, a adoção da modelagem matemática como estratégia de ensino e aprendizagem, pareceunos a mais adequada. (BASSANEZI, 2009, p.203-204).
\end{abstract}

A proposta inicial da Modelagem como estratégia de ensino e aprendizagem propiciou aos professores da educação básica refletir sobre a prática docente ao reconhecerem uma das possibilidades para estimular os alunos para as aulas de Matemática, assim como para melhorar e aprimorar as aulas desta disciplina.

Nesse sentido, as experiências iniciais de Modelagem com os professores possibilitaram incentivar a abertura de novos cursos no país tanto nas faculdades/universidades estaduais quanto federais:

\begin{abstract}
Os resultados obtidos desta experiência serviram de base para elaboração de outros cursos que seguiram tanto na FAFIG como em outras instituições de ensino: Faculdade Estadual de Filosofia, Ciências e Letras de Palmas-PR (FAFIP), Campo Mourão-PR (FECILCAM) e Dracena-SP (FAFID); Faculdade Estadual de Filosofia, Ciências e Letras de Cornélio Procópio-PR (FAFICOP) que é a atual Universidade Estadual do Norte do Paraná (UENP); Universidade Regional do Noroeste do Estado do Rio Grande do Sul (UNIJUÍ); Universidade Estadual PaulistaJúlio de Mesquita Filho (UNESP) de Guaratinguetá; Universidade de Mogi das Cruzes; Universidade de Marília; Universidade Federal de Cuiabá-MT; Universidade Estadual de Ponta Grossa-PR (UEPG); Universidade Federal de Mato Grosso (UFMT); Fundação da Universidade de Barretos-SP, e outros. (BASSANEZI, 2009, p. 204).
\end{abstract}

A abertura dessas instituições possibilita o oferecimento aos futuros professores de uma formação que contribua para utilizar-se a Modelagem;compreender-se o papel da Modelagem Matemática, do modelo matemático e do papel sociocultural da Matemática; formular e resolver problemas; e trabalhar com problemas a partir de situações concretas. A disciplina de Modelagem na formação inicial dos professores e também nos cursos de pós-graduação propicia o aprimoramento no modo de se refletir, entender e trabalhar com a Matemática, e não simplesmente tornar mais abrangente o conhecimento matemático.

A Modelagem nos cursos regulares, de capacitação ou especialização, pressupõe um plano de curso com objetivos bem definidos e norteados por diretrizes básicas como esclarece Bassanezi (2009):

- Dar condições aos professores para mudanças no conceito de prática educativa, liberando-os de alguns mitos com respeito ao uso de calculadores, rigor matemático, encadeamento de assuntos, avaliação, e outros;

- Desenvolver motivações para ações inovadoras que despertem a criatividade;

- Valorizar o conhecimento matemático no contexto global e seu poder de atuação em situações particularizadas; 
- Valorizar os recursos humanos disponíveis, explorar e desenvolver o talento dos cursistas-educadores para que se sintam capazes de contribuir com a comunidade em que trabalham;

- Ter em mente a interdisciplinaridade, aliando a Matemática às outras ciências para que sirva como instrumento de compreensão e de possíveis modificações da realidade;

- Inter-relacionar fatores experimentais e teóricos, isto é, não perder de vista a própria essência da "atitude matemática";

- Levar em conta as realidades específicas de cada região e os interesses dos estudantes, visando uma maior motivação e uma participação efetiva destes na comunidade, ou meios mais amplos dos quaispodem-se utilizar como cidadãos. Isto não significa adotar a tese popular de que "a ciência de um país em desenvolvimento deva ser regional" - o que seria um erro uma vez que a ciência busca explicações universais a partir de dados observáveis, ou não é ciência.

A Modelagem no processo de ensino e aprendizagem em cursos regulares, por exemplo, na educação básica ou na formação dos professores, desperta o interesse dos envolvidos por meio de problemas que estejam próximos da realidade do aluno. Logo, possibilita a reflexão da prática docente diante do campo de pesquisa e investigação da Educação Matemática por meio da Modelagem, bem como estimula o espírito inovador e a valorização da Matemática.

Segundo Bassanezi (2009, p.181-182), os objetivos da Modelagem Matemática como disciplina para a formação de professores são:

\footnotetext{
$\checkmark$ Enfatizar aplicações matemáticas, usando as técnicas de Modelagem como procedimentos, de modo a desenvolver, no educando, capacidades e atitudes criativas na direção da resolução de problemas;

$\checkmark$ Desenvolver o espírito crítico do educando de modo que ele possa entender e interpretar a Matemática em todas as suas facetas;

$\checkmark$ Preparar o educando para utilizar a Matemática como ferramenta para resolver problemas em diferentes situações e áreas;

$\checkmark$ Adotar um enfoque epistemológico alternativo associado a uma historiografia mais ampla, ou seja, partindo da realidade, encaminhando a ação cognitiva e a proposta pedagógica dentro de um enfoque cultural.
}

A Modelagem como disciplina na formação docente objetiva investigar e mostrar as aplicações da Matemática e dos modelos em diferentes áreas do conhecimento e níveis de ensino. Além disso, busca condicionar ao estudante o desenvolvimento de pesquisas e investigações, visto que este é conduzido a ser responsável pela sua própria aprendizagem, ou seja, desenvolver sua autonomia.

\section{ENCAMINHAMENTOS METODOLÓGICOS}

A seguir, apresenta-se um resumo de como foi organizada esta pesquisa:

Quadro 1 - Organização da Pesquisa Desenvolvida ORGANIZAÇÃO DA PESQUISA 


\begin{tabular}{|c|l|}
\hline & André (1986) e André (1998), a pesquisa foi qualitativa de cunho interpretativo. \\
\hline $\begin{array}{c}\text { Por que a pesquisa qua- } \\
\text { litativa é interpretativa? }\end{array}$ & $\bullet \begin{array}{c}\text { Prioriza ambiente natural de aprendizagem, o processo de ensino e aprendizagem; } \\
\text { Ções e compreensões dos sujeitos, e os dados obtidos na aplicação da pesquisa. }\end{array}$ \\
\hline $\begin{array}{c}\text { Procedimentos da } \\
\text { pesquisa }\end{array}$ & $\begin{array}{c}\text { Observação e análise dos dados obtidos nos endereços eletrônicos das insti- } \\
\text { tuições de ensino superior que estão cadastradas no "e-mec". }\end{array}$ \\
\hline
\end{tabular}

Fonte: Soares (2012, p.100).

A pesquisa desenvolvida encaminhou-se com caráter bibliográfico e os objetivos propostos foram atingidos por meio da observação e análise dos dados obtidos nos endereços eletrônicos das instituições de ensino superior que estão cadastradas no "e-mec".

\section{RESULTADOS E DISCUSSÕES}

De acordo com o exposto até o momento, foi realizada uma análise de modo conciso sobre os estados brasileiros que trabalham com o curso de Matemática na modalidade presencial das faculdades/universidades no sistema "e-mec".Este é um programa on-line do Ministério da Educação que possibilita a consulta das instituições de educação superior conforme a seleção do estado, curso e/ou municípios, como ilustra a tabela 1:

\section{Tabela 1 - Cursos Superiores de Matemática na Modalidade Presencial}

\begin{tabular}{|c|c|c|}
\hline Estados do Brasil & $\begin{array}{l}\text { Faculdades/Universidades em cada } \\
\text { Estado }\end{array}$ & $\begin{array}{l}\text { Porcentagem porEstado } \\
(\%)\end{array}$ \\
\hline Acre & 2 & $0,49 \%$ \\
\hline Amapá; Piauí; Roraima e Tocantins & $3(x 4)$ & $0,74 \%(x 4)$ \\
\hline Paraíba e Sergipe & $4(\mathrm{x} 2)$ & $0,98 \%(x 2)$ \\
\hline $\begin{array}{l}\text { Amazonas; Ceará; Maranhão e Rio } \\
\text { Grande do Norte }\end{array}$ & $5(x 4)$ & $1,23 \%(x 4)$ \\
\hline Alagoas; Rondônia e Pará & $6(x 3)$ & $1,47 \%(x 3)$ \\
\hline $\begin{array}{l}\text { Espírito Santo; Mato Grosso e Mato } \\
\text { Grosso do Sul }\end{array}$ & $7(\mathrm{x} 3)$ & $1,72 \%(x 3)$ \\
\hline Distrito Federal & 12 & $2,95 \%$ \\
\hline Goiás & 13 & $3,19 \%$ \\
\hline Bahia & 14 & $3,44 \%$ \\
\hline Pernambuco & 16 & $3,93 \%$ \\
\hline Santa Catarina & 17 & $4,18 \%$ \\
\hline Rio Grande do Sul & 26 & $6,39 \%$ \\
\hline
\end{tabular}




\begin{tabular}{ccc}
\hline Paraná & 28 & $6,88 \%$ \\
Rio de Janeiro & 34 & $8,35 \%$ \\
Minas Gerais & 54 & $13,27 \%$ \\
São Paulo & 112 & $27,52 \%$ \\
Total & $\mathbf{4 0 7}$ & $\mathbf{1 0 0 \%}$ \\
\hline
\end{tabular}

Fonte: E-mec (2012).

No Brasil, os cursos de Licenciatura e Bacharelado de Matemática se concentram significativamente nas regiões Sudeste e Sul. No Sudeste, o estado de São Paulo é o que mais oferece esses cursos correspondendo a 112 (27,52\%) das instituições do país e, no Sul, é o Paraná apresentando $28(6,88 \%)$ unidades de ensino superior. O Acre possui a menor quantidade de faculdades/universidades que oferta esses cursos, contando apenas com duas instituições que representam 0,49\% do cenário nacional. Os estados do Amapá, Piauí, Roraima e Tocantins, individualmente, possuem só três unidades de ensino superior desse curso. Isso aponta para uma escassez na formação dos professores de Matemática nessas regiões do país.

Nesse sentido, Bassanezi (2009, p. 179) explica que "sem dúvida, aproximando a nossa afirmação do terreno das conjeturas, com tal formação purista, os futuros profissionais só podem reconhecer a utilidade da Matemática na capacidade desta de ensinar a pensar e raciocinar com precisão". No Brasil, há vários cursos de Licenciatura em Matemática que não desenvolvem perspectivas interdisciplinares, multidisciplinares e/ou transdisciplinares de abordagem, bem como não incentivam a busca de conhecimento por meio de pesquisas que estimulam o espírito investigativo. Além disso, não orientam e estimulam o uso das novas tecnologias de informação e comunicação, como também das propostas e tendências educacionais, fazendo com que a Matemática se limite em torno dos conceitos disciplinares específicos.

Analisou-se também se as faculdades/ universidades do Paraná que ofertam cursos de Licenciatura em Matemática estão oferecendo a disciplina de "Modelagem Matemática" na matriz curricular. A obtenção dos dados se deu por meio de cada endereço eletrônico das instituições de ensino superior das faculdades/ universidades do curso relatado anteriormente do Paraná cadastradas no "e-mec".

\section{Quadro 2 - Disciplina de Modelagem Matemática inserida na Matriz Curricular}

\begin{tabular}{|c|l|c|}
\hline $\begin{array}{c}\text { Licenciatura de Matemática - Instituição no Pa- } \\
\text { raná }\end{array}$ & Tipo & Modelagem na Matriz Curricular \\
\hline $\begin{array}{c}\text { Faculdade de Apucarana - FAP } \\
\begin{array}{c}\text { Faculdade de Filosofia, Ciências e Letras de } \\
\text { Mandaguari - FAFIMAN }\end{array}\end{array}$ & Privada & Modelagem Matemática I e II \\
\hline $\begin{array}{c}\text { Faculdade Estadual de Ciências Econômicas de } \\
\text { Apucarana - FECEA à Modelagem Matemática }\end{array}$ & Pública & Modelagem Matemática \\
\hline $\begin{array}{c}\text { Faculdade Estadual de Ciências e Letras de Cam- } \\
\text { po Mourão - FECILCAM }\end{array}$ & Pública & $\begin{array}{c}\text { Modelagem Matemática na Perspectiva da } \\
\text { Educação Matemática }\end{array}$ \\
\hline
\end{tabular}




\begin{tabular}{|c|c|c|}
\hline $\begin{array}{c}\text { Faculdade Estadual de Educação, Ciências e } \\
\text { Letras de Paranavaí - FAFIPA }\end{array}$ & Pública & $\begin{array}{l}\text { Modelagem Matemática e Pesquisa Operacio- } \\
\text { nal }\end{array}$ \\
\hline $\begin{array}{l}\text { Faculdade Estadual de Filosofia, Ciências e Le- } \\
\text { tras União da Vitória - FAFIUV }\end{array}$ & Pública & Introdução à Modelagem Matemática \\
\hline Faculdade Unilagos - UNILAGOS & Privada & Modelagem Matemática \\
\hline Universidade Estadual de Londrina - UEL & Pública & $\begin{array}{c}\text { Modelagem Matemática na Perspectiva da } \\
\text { Educação Matemática }\end{array}$ \\
\hline Universidade Estadual de Maringá - UEM & Pública & Modelos e Modelagem Matemática (optativa) \\
\hline $\begin{array}{l}\text { Universidade Estadual do Centro-Oeste - UNI- } \\
\text { CENTRO }\end{array}$ & Pública & $\begin{array}{c}\text { Modelagem Matemática na Educação Mate- } \\
\text { mática (optativa) }\end{array}$ \\
\hline $\begin{array}{c}\text { Universidade Estadual do Norte do Paraná - } \\
\text { UENP }\end{array}$ & Pública & Introdução à Modelagem Matemática \\
\hline $\begin{array}{c}\text { Universidade Tecnológica Federal do Paraná - } \\
\text { UTFPR }\end{array}$ & Pública & $\begin{array}{c}\text { Modelagem Matemática (só no campus Pato } \\
\text { Branco é optativa). }\end{array}$ \\
\hline Total & 12 & \\
\hline
\end{tabular}

Fonte: Soares (2012, p.44).

$\mathrm{O}$ autor mencionado anteriormente relata que, se a ênfase das propostas de melhorar a Educação Matemática está mais nos modelos que na teoria, querendo-se a Matemática elegante e aplicável, que o professor sinta-se valorizado ao ensiná-la, precisa-se questionar e repensar o currículo da Licenciatura em Matemática (BASSANEZI, 2009, p.181). Com isso, notase a importância do currículo eficiente nos cursos para formação de professores de Matemática, pois é essencial este apresentar um equilíbrio harmonioso entre a teoria e a prática e, para tanto, se tem a Modelagem Matemática que é uma das tendências de ensino.

A partir das considerações apresentadas tem-se a tabela a seguir:

\section{Tabela 2 - Análise da Disciplina de Modelagem Matemática inserida na} Matriz Curricular

\begin{tabular}{ccc}
\hline $\begin{array}{c}\text { Faculdades/ } \\
\text { Universidades }\end{array}$ & Modelagem Matemática está na Matriz Curricular & $\begin{array}{c}\text { Porcentagem } \\
(\%)\end{array}$ \\
Públicas & 09 & $32,14 \%$ \\
Privadas & 03 & $10,71 \%$ \\
Total & $\mathbf{1 2}$ & $\mathbf{4 2 , 8 5 \%}$ \\
\hline
\end{tabular}

Fonte: Soares (2012, p.46). 
No estado do Paraná há 28 cursos superiores de Licenciatura em Matemática, nos quais a disciplina de Modelagem não aparece em todas as matrizes curriculares, pois ela está presente em apenas 12 instituições, sendo que 9 destas trabalham-na como disciplina obrigatória enquanto que 3 destas como optativa. A Modelagem se encontra na matriz de 9 instituições públicas, que expressam $32,14 \%$, enquanto que as privadas contam com 3 , que significam $10,71 \%$. Infere-se que só $42,85 \%$ do total das faculdades/universidades que ofertam esse curso superior trabalham a Modelagem com os futuros professores.

A Modelagem nos cursos de Licenciatura em Matemática no Brasil teve seu início do seguinte modo, como esclarece Bassanezi (2009, p.181):

\begin{abstract}
Vale aqui ressaltar que consideramos ter dado, no Instituto de Matemática, Estatística e Computação Científica da Universidade Estadual de Campinas (IMECC/UNICAMP), os primeiros passos para transformar o problema da formação do professor de matemática, ao implantar a disciplina "Modelos Matemáticos", ministrada no programa de Licenciatura em Matemática (curso vespertino). O enfoque central desta disciplina é procurar um equilíbrio harmonioso entre a teoria e a prática, mostrando o valor intrínseco da matemática, assim como sua plasticidade e beleza, enquanto ferramenta para outras áreas do conhecimento.
\end{abstract}

A Modelagem na formação dos professores de Matemática enfatizou as aplicações matemáticas na sociedade e desenvolveu habilidades e aptidões ao resolver e solucionar problemas. Dessa forma, permitiu que se trabalhasse com problemas da realidade buscando mostrar a aplicação da Matemática nos temas sociais, investigando e analisando a natureza dos modelos matemáticos.

Então, as práticas de Modelagem permitiram obter mudanças no ensino:

As experiências com os cursos de aperfeiçoamento transformaram nossa postura como educador, evidenciada nos cursos regulares da Universidade Estadual de Campinas (UNICAMP), em projetos de iniciação científica, e mesmo em projetos de pesquisa. Em um segundo momento foi criada, no Instituto de Matemática, Estatística e Computação Científica (IMECC), a área de Biomatemática (Mestrado e Doutorado). Nesse, temos atuado como orientadores, onde alguns dos projetos de pesquisa são provenientes de questionamentos surgidos nos cursos de Especialização e Aperfeiçoamento que temos coordenado, já que tais cursos têm o potencial de gerar propostas para estudos mais avançados, funcionando como fontes geradoras de problemas e temas de pesquisa. (BASSANEZI, 2009, p.204).

As práticas de Modelagem nos cursos regulares, por meio de trabalhos e projetos, permitiram novas transformações e contribuições para a postura docente e envolvimento discente nas aulas. Observa-se que os resultados satisfatórios das práticas e trabalhos de Modelagem foram divulgados pelos projetos, cursos de aperfeiçoamento, de graduação e de pósgraduação.

A seguir, têm-se as faculdades/universidades do Paraná que não oferecem a disciplina de Modelagem na matriz do curso de Licenciatura em Matemática:

\title{
Quadro 3 - Disciplina de Modelagem Matemática não inserida na Matriz Curricular
}




\begin{tabular}{|c|c|c|}
\hline $\begin{array}{l}\text { Licenciatura de Matemática - } \\
\text { Instituição do Paraná }\end{array}$ & Tipo & Modelagem na Matriz Curricular \\
\hline $\begin{array}{c}\text { Centro Técnico-Educacional Su- } \\
\text { perior do Oeste Paranaense - } \\
\text { CTESOP }\end{array}$ & Privada & Não \\
\hline $\begin{array}{l}\text { Centro Universitário Campos de } \\
\text { Andrade - UNIANDRADE }\end{array}$ & Privada & Não \\
\hline Faculdade da Fronteira - FAF & Privada & Não \\
\hline $\begin{array}{l}\text { Faculdade de Ensino Superior de } \\
\text { São Miguel do Iguaçu - FAESI }\end{array}$ & Privada & Não \\
\hline Faculdade de Ampére - FAMPER & Privada & Não. Porém, tem "Tendências em Educação Matemática". \\
\hline Faculdade Guairaçá - FAG & Privada & Não \\
\hline $\begin{array}{l}\text { Faculdades Integradas do Vale do } \\
\text { Ivaí - UNIVALE }\end{array}$ & Privada & Não. Porém, tem “Tópicos em Educação Matemática I e II”. \\
\hline $\begin{array}{l}\text { Pontifícia Universidade Católica } \\
\text { do Paraná - PUC-PR }\end{array}$ & Privada & Não \\
\hline $\begin{array}{l}\text { Universidade Estadual de Ponta } \\
\text { Grossa - UEPG }\end{array}$ & Pública & $\begin{array}{c}\text { Não. Porém, tem "Modelos" e "Pesquisa em Educação Ma- } \\
\text { temática". }\end{array}$ \\
\hline $\begin{array}{l}\text { Universidade Federal do Paraná - } \\
\text { UFPR }\end{array}$ & Pública & $\begin{array}{l}\text { Não. Porém, tem a disciplina “Educação Matemática I" e } \\
\text { "Modelos Matemáticos em Finanças" (optativas). }\end{array}$ \\
\hline $\begin{array}{l}\text { Universidade Paranaense - UNI- } \\
\text { PAR }\end{array}$ & Privada & Não \\
\hline $\begin{array}{l}\text { Universidade Tuiuti do Paraná - } \\
\text { UTP }\end{array}$ & Privada & $\begin{array}{c}\text { Não. Porém, tem "Fundamentos Didáticos da Educação } \\
\text { Matemática". }\end{array}$ \\
\hline $\begin{array}{l}\text { Universidade Estadual do Oeste } \\
\text { do Paraná - UNIOESTE }\end{array}$ & Pública & $\begin{array}{l}\text { Não. Porém, tem: “Tendências em Educação Matemática”, } \\
\text { em Cascavel. "Psicologia Aplicada à Educação Matemática; } \\
\text { A Informática Aplicada à Educação Matemática; Estatística } \\
\text { Aplicada à Educação Matemática”; em Foz do Iguaçu. }\end{array}$ \\
\hline $\begin{array}{l}\text { Faculdades Integradas Camões - } \\
\text { FICA }\end{array}$ & Privada & Sem disponibilização da matriz curricular. \\
\hline $\begin{array}{c}\text { Faculdade Estadual de Filosofia, } \\
\text { Ciências e Letras de Paranaguá - } \\
\text { FAFIPAR }\end{array}$ & Pública & Sem disponibilização da matriz curricular. \\
\hline $\begin{array}{c}\text { Faculdade de Ciências, Letras e } \\
\text { Educação do Noroeste do Paraná } \\
\text { - FACLENOR }\end{array}$ & Privada & Sem disponibilização de acesso on-line. \\
\hline Total & 16 & $\longrightarrow$ \\
\hline
\end{tabular}

Fonte: Soares (2012, p.47) 
Então, os futuros professores de Matemática que não receberem uma preparação para trabalhar com a Modelagem poderão apresentar dificuldades para futuras práticas que apresentem a Matemática no cotidiano relacionando a teoria à prática, assim como resistências e obstáculos em reconhecer o processo da Modelagem e sua importância para o ensino e aprendizagem de Matemática. Com essas considerações tem-se a tabela a seguir:

Tabela 3 - Análise da Disciplina de Modelagem Matemática não inserida na Matriz Curricular

\begin{tabular}{ccc}
\hline $\begin{array}{c}\text { Faculdades/ universi- } \\
\text { dades }\end{array}$ & Modelagem Matemática não está na Matriz Curricular & Porcentagem (\%) \\
Públicas & 04 & $14,29 \%$ \\
Privadas & 12 & $42,86 \%$ \\
Total & $\mathbf{1 6}$ & $\mathbf{5 7 , 1 5 \%}$ \\
\hline
\end{tabular}

Fonte: Soares (2012, p.49).

A maioria das instituições de ensino superior do estado do Paraná que ofertam o curso de Licenciatura em Matemática não trabalha com a Modelagem no programa deste curso. Todavia, somente algumas instituições buscam abordar alguma disciplina que pode se direcionar à Modelagem, por exemplo, ao discutir sobre Educação Matemática, tendências e pesquisas referentes a isto, modelos e/ou à informática aplicada nesta educação. Com isso, possibilita-se refletir e entender algumas alternativas que sejam capazes de melhorar o ensino e a aprendizagem de Matemática.

A Modelagem já é bastante discutida em relação as suas contribuições para o ensino, desperta motivações nos envolvidos, permite reconhecer o papel da Matemática na sociedade e suas aplicações, o desenvolvimento do espírito inovador e transformador, porém não é considerada fácil por diversos alunos. Assim, não é uma tarefa simples devido às dificuldades para inseri-la em sala de aula. Isso pode ser um dos motivos pelos quais a maioria das universidades/faculdades não procura oferecer a Modelagem na matriz curricular, visto que as instituições privadas representam em 12 , ou seja, $42,86 \%$, já as públicas são 4 , que expressam 14,29\%. Desse modo, os futuros professores de Matemática do estado do Paraná poderão apresentar resistências e obstáculos em reconhecer o processo da Modelagem e sua importância ao ensino e aprendizagem.

Nesta análise desenvolvida, infere-se que as faculdades/universidades que abordam a Modelagem em seu curso não podem afirmar que todos os futuros professores estarão preparados para trabalhá-la em sala de aula, porém terão possibilidades de refletir para aprimorar seus conhecimentos a este respeito. Para as instituições públicas e privadas que não oferecem a Modelagem em sua estrutura curricular, os licenciandos podem apresentar uma concepção considerando a Matemática sistêmica e abstrata, na qual o aluno é identificado como passivo, o docente como autoritário e a Matemática sem conexão cotidiana.

\section{CONSIDERAÇÕES FINAIS}

Neste artigo, percebeu-se a relevância de discutir e abordar a Modelagem nos cursos regulares como os de educação básica, graduação e pós-graduação. Com a análise desenvolvida, 
infere-se que o objetivo proposto foi atingido, pois se observou que é uma pequena quantidade de instituições de ensino do país, tanto públicas quanto privadas, que trabalham a disciplina de Modelagem Matemática no curso de Licenciatura em Matemática. Isso foi notório no Paraná, estado em que se concentrou esta pesquisa, onde se percebeu que várias faculdades/universidades não a integram em sua matriz curricular como disciplina obrigatória ou optativa.

Apesar de a Modelagem ser pouco explorada nos cursos regulares como disciplina, alguns pesquisadores discutem e analisam a importância de abordá-la no currículo dos cursos como os de graduação, lato sensu (especialização), stricto sensu (mestrado e doutorado) e nas práticas de ensino. Além disso, ela vem sendo amplamente divulgada, crescendo gradativamente por meio de pesquisas e práticas, as quais são difundidas em bibliotecas físicas e online, na forma de cursos, programas, revistas, livros, eventos, congressos e outros. A partir desses elementos, considera-se possível sua implementação nas práticas da educação básica, como disciplina nas instituições de ensino e na formação de professores para atuarem no ensino fundamental e médio e em outros níveis de ensino.

A Modelagem inserida na matriz do curso de Licenciatura em Matemática tem por fundamento incentivar e possibilitar uma preparação dos futuros professores para compreenderem e trabalharem com a Modelagem no ensino. Além disso, motiva-os para a aprendizagem Matemática e propicia condições para valorizá-la,investigá-la e aplicá-la em situações da realidade. Assim, é de suma importância propiciar aos licenciandos o reconhecimento e entendimento dessa tendência da Educação Matemática, assim como seu desenvolvimento e aplicabilidade.

Nessa perspectiva, a Modelagem como disciplina na formação dos professores de Matemática permite que os licenciandos analisem, selecionem e organizem informações e dados para desenvolverem atividades de Modelagem no ensino possibilitando tornar as aulas de Matemática mais dinâmicas, flexíveis no pensamento matemático e com autonomia no processo de ensino e aprendizagem. Dessa forma, a respeito da Matemática presente no cotidiano, temse mais interesse em pesquisá-la, investigá-la e compreendê-la propiciando estímulos para novas ideias, descobertas, conhecimentos, experiências, aprendizagens e ações inovadoras.

Portanto, infere-se que há inúmeros professores que não reconhecem e entendem o processo da Modelagem apresentando resistências a ela. Esse é um dos motivos pelo qual não é muito trabalhada em sala de aula. Logo, há uma minoria de instituições de ensino superior do estado do Paraná que a trabalham como disciplina no curso de Licenciatura em Matemática, pois poucos professores estão interessados em entendê-la e/ou trabalhá-la, tanto pelo fato de não estarem preparados para explorá-la em sala de aula quanto pelas dificuldades encontradas para aplicá-la com os sujeitos.

\section{REFERÊNCIAS}

ANDRÉ, M. E. D. A. Etnografia da Prática Escolar. 2. ed. Campinas: Papirus, 1998.

BARBOSA, J. C. Modelagem Matemática na Sala de Aula. Perspectiva, Erechim, v. 27, n. 98, jun. 2003. Disponível em: <http://www.uefs.br/nupemm/perspectiva.pdf>. Acesso em: 09 mar. 2012. 
SOARES, M. R.. Modelagem Matemática:concepções e experiências de futuros professores. 253 f. Tese (Doutorado em Educação Matemática) - Instituto de Geociências e Ciências Exatas, Universidade Estadual Paulista Júlio de Mesquita Filho de Rio Claro, UNESP, Rio ClaroSP, 2001.

BASSANEZI, R. C.Ensino-aprendizagem com Modelagem Matemática.3. ed. São Paulo: Contexto, 2009.

BLUM, W. Applications and Modelling in mathematics teaching and mathematics education - some important aspects of practice and of research. In: SLOYER, C. et al. Advances and perspectives in the teaching of mathematical modelling and applications. Yorklyn: Water Street Mathematics, 1995. p. 1-20.

BRASIL, Ministério da Educação. E-mec. Instituições de Educação Superior e Cursos Cadastrados. Consulta Interativa - Paraná. Disponível em: <http://emec.mec.gov.br/>. Acesso em: 02 mar. 2012.

CENTRO TÉCNICO-EDUCACIONAL SUPERIOR DO OESTE PARANAENSE (CTESOP).Matriz Curricular do Curso de Licenciatura em Matemática.Disponível em: <http://www.unimeo.com.br/graduacao/matematica/grade-curricular.html>. Acesso em: 05 mar. 2012.

CENTRO UNIVERSITÁRIO CAMPOS DE ANDRADE (UNIANDRADE).Matriz Curricular do Curso de Licenciatura em Matemática.Disponível em: <http://www.uniandrade.br/curso_matematica.php>. Acesso em: 05 mar. 2012.

CHEVALLARD, Y. et al. Estudar Matemáticas: o elo perdido entre o ensino e a aprendizagem. Porto Alegre: Artmed,2001.

FACULDADE DA FRONTEIRA (FAF).Matriz Curricular do Curso de Licenciatura em Matemática.Disponível em: <http://www.faf.edu.br/>. Acesso em: 05 mar. 2012.

FACULDADE DE AMPÉRE (FAMPER).Matriz Curricular do Curso de Licenciatura em Matemática. Disponível em:<http://www.famper.com.br/2010/arquivos/matriz_matematica_site.pdf $>$. Acesso em: 05 mar. 2012.

FACULDADE DE APUCARANA (FAP). Matemática com Ênfase em Informática. Grade Curricular por Créditos e Status.Matriz Curricular do Curso de Licenciatura em Matemática.Disponível

em:〈http://www.fap.com.br/website/graduacao/matematica/matriz/matrizcurricular.pdf>. Acesso em: 05 mar. 2012.

FACULDADE DE ENSINO SUPERIOR DE SÃO MIGUEL DO IGUAÇU (FAESI).Matriz Curricular do Curso de Licenciatura em Matemática.Disponível em:

<http://www.camoes.edu.br/site/Graduacao/licenciatura-em-matematica.html>. Acesso em: 05 mar. 2012. 
FACULDADE DE FILOSOFIA, CIÊNCIAS E LETRAS DE MANDAGUARI (FAFIMAN).Matriz Curricular do Curso de Licenciatura em Matemática.Disponível em: <http://www.vestibularfafiman.com.br/curso/10/matematica.html>. Acesso em: 05 mar. 2012.

FACULDADE ESTADUAL DE CIÊNCIAS ECONÔMICAS DE APUCARANA (FECEA). Distribuição da carga horária das disciplinas do curso de Licenciatura em Matemática.Matriz Curricular do Curso de Licenciatura em Matemática.Disponível em: <http://www.fecea.br/userfiles/GRADE.pdf>. Acesso em: 05 mar. 2012.

FACULDADE ESTADUAL DE CIÊNCIAS E LETRAS DE CAMPO MOURÃO (FECILCAM).Matriz Curricular do Curso de Licenciatura em Matemática.Disponível em:

<http://www.fecilcam.br/academico/index.php?option=com_docman\&task=cat_view\&gid=5 \&dir=ASC\&order=name\&Itemid=7\&limit=5\&limitstart=10>. Acesso em: 05 mar. 2012.

FACULDADE ESTADUAL DE EDUCAÇÃO,CIÊNCIAS E LETRAS DE PARANAVAÍ(FAFIPA). Matriz Curricular do Curso de Licenciatura em Matemática.Disponível em:

<http://www.fafipa.br/index.php?option=com_content\&view=article\&id=281\&Itemid=405> . Acesso em: 05 mar. 2012.

FACULDADE ESTADUAL DE FILOSOFIA, CIÊNCIAS E LETRAS DE PARANAGUÁ(FAFIPAR). Curso de Licenciatura em Matemática. Disponível em: <http://www.fafipar.br/index.jsp?conteudo=12>. Acesso em: 05 mar. 2012.

FACULDADE ESTADUAL DE FILOSOFIA, CIÊNCIAS E LETRAS UNIÃO DA VITÓRIA(FAFIUV).Matriz Curricular do Curso de Licenciatura em Matemática. Disponível em: 〈http://www.fafiuv.br/matematica.php〉. Acesso em: 05 mar. 2012.

FACULDADE GUAIRAÇÁ (FAG).Matriz Curricular do Curso de Licenciatura em Matemática.Disponível em:

<http://www.faculdadeguairaca.edu.br/arcs/fg_graduacao_matriz_matriz_matematica.pdf >. Acesso em: 05 mar. 2012.

FACULDADES INTEGRADAS CAMÕES (FICA).Curso de Licenciatura em Matemática.Disponível em:

$<$ http://www.camoes.edu.br/site2/index.php?option=com_content \&view=article\&id=188\&Ite mid=250>. Acesso em: 05 mar. 2012.

FACULDADES INTEGRADAS DO VALE DO IVAÍ (UNIVALE).Matriz Curricular do Curso de Licenciatura em Matemática. Disponível em:

<http://www.univale.com.br/unisite/index.php?link=4\&c=19>. Acesso em: 05 mar. 2012.

FACULDADE UNILAGOS (UNILAGOS).Matriz Curricular do Curso de Licenciatura em Matemática.Disponível em:

<http://www.unilagos.com.br/matematica/pdf/grade_matematica.pdf>. Acesso em: 05 mar. 2012.

LINCOLN, Y. S.; GUBA, E. G. NaturalisticInquiry.Newbury Park: Sage, 1985. 
LÜDKE, M.; ANDRÉ, M. E. D. A.Pesquisa em educação: abordagens qualitativas.São Paulo: EPU, 1986.

MILES, M. B.; HUBERMAN, A. N. Qualitative data analysis: an expanded sourcebook. 2.ed. Thousand Oaks: Sage, 1994.

PONTIFÍCIA UNIVERSIDADE CATÓLICA DO PARANÁ (PUC-PR).Matriz Curricular do Curso de Licenciatura em Matemática. Disponível em:

<http://www.pucpr.br/graduacao/matematica/estrutura.php5>. Acesso em: 06 mar. 2012.

SOARES, M. R. Modelagem matemática como estratégia de ensino e aprendizagem:uma perspectiva à luz dos futuros professores de matemática.312f. Dissertação (Mestrado em Ensino de Ciência e Tecnologia) - Programa de Pós-Graduação em Ensino de Ciência e Tecnologia, Universidade Tecnológica Federal do Paraná, UTFPR, Ponta Grossa, 2012. Disponível em:

<http://www.pg.utfpr.edu.br/dirppg/ppgect/dissertacoes/defesas.php?ano=2012\&grupo=0>. Acesso em: 10 jan. 2013.

UNIVERSIDADE ESTADUAL DE LONDRINA (UEL).Matriz Curricular do Curso de Licenciatura em Matemática. Disponível em: <http://www.uel.br/prograd/catalogocursos/catalogo_2011/organizacao_curricular/matematica_licenciatura.pdf >. Acesso em: 06 mar. 2012.

UNIVERSIDADE ESTADUAL DE MARINGÁ (UEM0.Matriz Curricular do Curso de Licenciatura em Matemática. Disponível em:<http://www.pen.uem.br/html/pen/graduacao/cursos/mat.pdf $>$. Acesso em: 06 mar. 2012.

UNIVERSIDADE ESTADUAL DE PONTA GROSSA (UEPG).Matriz Curricular do Curso de Licenciatura em Matemática. Disponível em:

<http://www.uepg.br/Catalogo/setor1/matematica.pdf>. Acesso em: 06 mar. 2012.

UNIVERSIDADE ESTADUAL DO CENTRO-OESTE (UNICENTRO).Matriz Curricular do Curso de Licenciatura em Matemática. Disponível em:<http://www.unicentro.br/proen/grades/MATEM\%C3\%81TICA.pdf >. Acesso em: 06 mar. 2012.

UNIVERSIDADE ESTADUAL DO NORTE DO PARANÁ (UENP).Matriz Curricular do Curso de Licenciatura em Matemática.Disponível em: $<$ http://www.uenp.edu.br/prograd/index.php?option=com_content\&view=article\&id=72\& Itemid=82>. Acesso em: 06 mar. 2012.

UNIVERSIDADE ESTADUAL DO OESTE DO PARANÁ (UNIOESTE).Matriz Curricular do Curso de Licenciatura em Matemática. Disponível em:<http://www.unioeste.br/prg/>. Acesso em: 06 mar. 2012.

UNIVERSIDADE FEDERAL DO PARANÁ (UFPR). Matriz Curricular do Curso de Licenciatura em Matemática. Disponível em:<http://www.mat.ufpr.br/graduacao/matematica/curriculo/lic_noite.html>. Acesso em: 06 mar. 2012. 
UNIVERSIDADE PARANAENSE (UNIPAR).Matriz Curricular do Curso de Licenciatura em Matemática. Disponível em:

<http://www.unipar.br/media/arquivos/matrizes/Matematica.pdf>. Acesso em: 06 mar. 2012.

UNIVERSIDADE TECNOLÓGICA FEDERAL DO PARANÁ (UTFPR).Matriz Curricular do Curso de Licenciatura em Matemática. Disponível em:

<http://www2.utfpr.edu.br/estrutura-universitaria/pro-reitorias/prograd/cursos/licenciaturas>. Acesso em: 06 mar. 2012.

UNIVERSIDADE TUIUTI DO PARANÁ (UTP).Matriz Curricular do Curso de Licenciatura em Matemática. Disponível em:

<http://www.utp.br/cursos/facet/ML/GradeCurricular-ML_.pdf>. Acesso em: 06 mar. 2012. 